\title{
Fatigue Behaviour of Composite T-Joints in Wind Turbine Blade Applications
}

\author{
Y. Wang ${ }^{1} \cdot$ C. Soutis ${ }^{1}$
}

Received: 31 August 2016/Accepted: 30 September 2016/Published online: 18 October 2016

(C) The Author(s) 2016. This article is published with open access at Springerlink.com

\begin{abstract}
This paper presents a study of fatigue performance of composite T-joints used in wind-turbine blades. A T-joint with various fibre reinforcement architectures were selected to investigate its fatigue behaviour. The 3D angle interlock T-joint was found to have the best performance in both static and fatigue loading. Increasing the static properties increases fatigue performance while the increasing rate in life performance is changed with the number of fatigue cycles. A finite element (FE) model was developed that can determine the stress distribution and the initiation and propagation of a delamination crack. The location for through-thickness reinforcement is very important to improve fatigue performance of composite T-joints. Fatigue performance is significantly improved for the web with through-thickness reinforcement while fatigue performance is decreased if the through-thickness reinforcement is applied to the flange-skin regions. The interlaminar veil significantly increases the ultimate strength under static load but fatigue performance at high stress cycles is increased but not significantly.
\end{abstract}

Keywords Composite structures $\cdot$ T-joint $\cdot$ Finite element analysis $\cdot$ Fatigue $\cdot$ Delamination

\section{Introduction}

A typical wind turbine blade when in service is subjected to flexural bending that induces tensile and compressive stresses and torsion that leads to development of shear stresses. Beside these, the wind blade must endure several orders of magnitude more cycles of fatigue loading than an aircraft, which makes wind turbines fatigue critical structures. The wind-turbine blades are often made of composite materials due to their low density and excellent mechanical properties combination of strength, stiffness, fatigue performance and better corrosion resistance than metals [1]. Wind turbine blade failures, when in service are due to various complicated reasons but blade failures account for most accidents and damage to wind turbines

C. Soutis

constantinos.soutis@manchester.ac.uk

1 School of Materials, University of Manchester, James Lighthill Building, Sackville Street, Manchester M1 3NJ, UK 
[2]. Therefore, it is important to understand the way the composite T-joint fails and develop methods of improving fatigue life performance to enhance the durability of wind turbines.

The composite materials used in blade construction are typically fabrics containing a variety of configurations (e.g. non-crimp fabrics (NCF), uniweave and woven). The formation of internal detailed shapes within the blade, allowing features such as spars, shear webs and other connections, inevitably requires these 2D material configurations to be formed into three-dimensional (3D) shapes. This introduces sites within the structure where load transfer occurs across regions with little or no fibre reinforcement. These weak areas become natural positions for the initiation of delamination. To overcome this problem, through-thickness reinforcement is widely considered to be an efficient way to increase the resistance of laminated composites and bonded joints against out-of-plane failures. Various techniques, such as stitching, interlaminar veils, braiding, knitting, weaving and z-pining have been developed to improve the properties in the throughthickness direction [3-8]. Numerous studies have developed finite element models to simulate and predict the delamination of a composite T-joint [9-16]. Failure of composite T-joints has also been studied experimentally from different point of view by many investigators [5, 17-26]. The properties of these composite T-joints and possible toughening methods to improve thoroughthickness properties very much depend on the manufacturing method of the part.

The effort to improve fatigue performance of composite materials has been carried out over the past 20 years; a number of scientific and technical issues still need to be resolved, for example, predictive models for determining the strength of T-joints with various reinforcement configurations have not been satisfactorily developed. A detail analysis of composite T-joint with various reinforcement configurations has not been attempted so far, and it is the subject of the paper.

In this study, a T-section was selected as a representative structural part to simulate a realistic part of the blade structure. The T-section has been manufactured as representative element of the blade's Spar. T-sections have been made of glass fabric infused with epoxy resin using a vacuum assisted resin transfer moulding (RMT) technique. Methods such as the use of veil layers, tufting techniques have been utilised to improve delamination resistance. A finite element model was developed that can determine the initiation and propagation of delamination crack in the composite T-joints with various reinforcement architectures. Fatigue tests on different T-joint configurations were conducted in earlier work [27] and used to validate the FE model. Experimental measurements and FE analysis are presented and discussed in the following sections.

\section{Experimental Measurements}

\subsection{Materials and Test Conditions}

In this section a brief description of the fabrication method and mechanical tests performed on the selected T-joints is given. Further experimental details can be found in references [27].

The T-joint specimens selected for the test were made of glass fabric infused with epoxy resin using a veil layer, 3D weave and tufting between the flange and the skin to improve the inter-laminar fracture toughness. The geometry of T-joint is shown in Fig. 1 and layup details are listed in Table 1. The resin is an epoxy based on Araldite LY 564, and the associated hardener used is a formulated amine based on XB 3486. Both resin and hardener were supplied by Huntsman. Two different types of fibre glass were used in this experiment. Unidirectional E glass fibre (FGE664) was used for the outer stiffener (support plate) and $\pm 45^{\circ}$ glass fibre (FGE104) was used in the fabrication of the web, flange and skin of the T- 


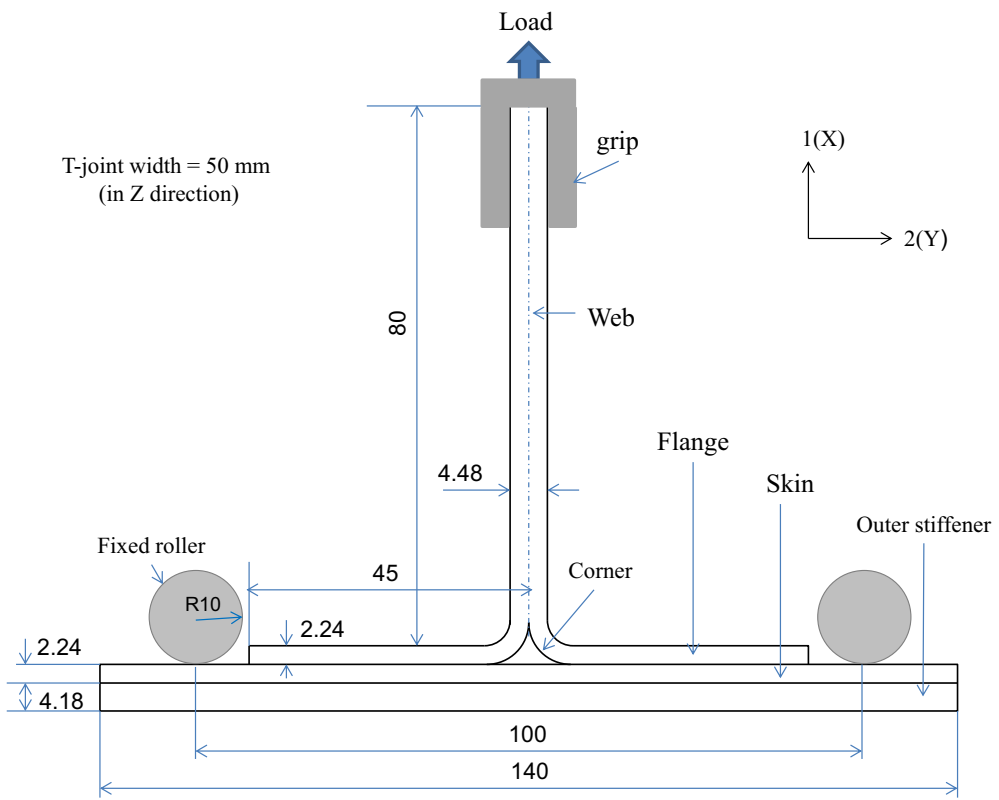

Fig. 1 Geometry and loading condition of a composite T-joint (all dimension in $\mathrm{mm}$ ). The outer stiffener is used to constrain larger displacement

joint. Both of these fabrics were manufactured by Formax. The areal density for $\left[ \pm 45^{\circ}\right]$ and UD fabrics is 609 and $594 \mathrm{~g} / \mathrm{m}^{2}$, respectively.

A non-woven tissue fabric (polyester veil) was added between the flange and the skin in order to increase interlaminar fracture toughness of the T-joint. The thickness of the polyester veil is $0.055 \mathrm{~mm}$ and the areal density is $15 \mathrm{~g} / \mathrm{m}^{2}$. Tufting material used for out-of-plane stitching was a 120 tex Kevlar-29 thread with tenacity of 185$200 \mathrm{cN} /$ tex from Atlantic Thread and Supply. Stitch density was $10 \mathrm{~mm}$ in the length direction and $10 \mathrm{~mm}$ in the width direction.

3D fabrics were selected to manufacture the composite T-joints in order to study the effect of out of plane reinforcement in the web. The structure was weaved as a flat panel and from halfway in width the middle layer was removed during the weave process and a gap in thickness produced. The woven panel was then opened up from this gap and the two flange

Table 1 Sample specifications

\begin{tabular}{|c|c|c|}
\hline Type & Architectures & Description \\
\hline Base & $\begin{array}{l}\text { Web: }[ \pm 45]_{10} \text { Flange-Skin-Stiffener: } \\
\qquad[ \pm 45]_{5}[ \pm 45]_{5}[0]_{5}\end{array}$ & T-joint made from glass fibre and epoxy matrix \\
\hline Polyester veil (PE) & $\begin{array}{l}\text { Web: }[ \pm 45]_{10} \text { Flange-Skin-Stiffener: } \\
\quad[ \pm 45]_{5}[\mathrm{PE}][ \pm 45]_{5}[0]_{5}\end{array}$ & $\begin{array}{l}\text { Type Base T-joint }+ \text { polyester veil added } \\
\text { between the flange and the skin }\end{array}$ \\
\hline Tufted & $\begin{array}{l}\text { Web: }[ \pm 45]_{10} \text { Flange-Skin-Stiffener: } \\
\quad[ \pm 45]_{5}[ \pm 45]_{5}[0]_{5}\end{array}$ & $\begin{array}{l}\text { Type Base T-joint }+ \text { reinforced with Kevlar } \\
\text { thread in the through-thickness direction on } \\
\text { flange-skin-stiffener }\end{array}$ \\
\hline 3D-An & Web: 3DAn Flange-Stiffener: $3 D A n[0]_{5}$ & $\begin{array}{l}\text { T-joint made from 3D Woven fabric } \\
\text { (3D Angle Interlocked) }\end{array}$ \\
\hline
\end{tabular}


sections of the joint were formed on each sides of the web. The fibre type used in the 3D weaves is E-glass.

Static behaviour of the T-joints with various configurations was tested under tensile pull-out loading to obtain the ultimate failure load of the T-joints. An Instron testing machine was employed to perform the mechanical tests at a loading rate of $2 \mathrm{~mm} / \mathrm{min}$. Load and displacement values were recorded during tests. A criterion to terminate the test was set as either a $40 \%$ drop in the measured load or a total delamination length of $50 \mathrm{~mm}$.

Fatigue test was performed in a load control mode with a stress ratio of $R=\sigma_{\min } / \sigma_{\max }=0.1$. The cyclic loading pattern was a sinusoidal wave at a frequency of $6 \mathrm{~Hz}$ while the thermal effect is not considered at this test frequency. The specimens were cycled at a series of constant maximum load values up to failure. Fatigue load levels were chosen with regards to maximum pull-out strength of samples obtained in the static tensile test. This allowed a complete knowledge of the stress-life relationship ( $S$ - $N$ curves) of T-joints with different configurations. Constant fatigue load versus life data for each T- joint type were produced at various constant maximum applied loads. Failure criteria for fatigue tests were either crack length of $25 \mathrm{~mm}$ on each side of the web or one million fatigue cycles. Visual observations of each specimen were also undertaken at intervals during testing, and a record was made of any damage observed.

\subsection{Stress-Deflection Curves}

In this study, T-joints were made of glass fabric infused with using a vacuum-assisted resin transfer moulding (RTM). This will lead to the variation in the thickness of both base plate (flange-skin-stiffener) and web with different batches of test specimen. To remove the effect of specimen geometry, the test results were normalised on the base plate section. Taking into account the effect of bending, the maximum nominal stress in $y$ - direction occurring in the base plate (Fig. 1) is calculated using the beam bending theory [28] and the maximum nominal stress $\left(\sigma_{2}\right)$ can be expressed as follow:

$$
\sigma_{2}=\frac{3 L}{2 b}\left(\frac{P}{h^{2}}\right)
$$

Here $P$ is the applied load, $L$ is the span of T-joint, $h$ is the total thickness of the base section and $b$ is the width of T-joint. When the span $(L)$ and the width $(b)$ is fixed the magnitude of the stress occurred on the surface is inversely proportional to the square of the thickness $(h)$. In other words, the stress value is sensitive to the change of the base plate thickness.

Figure 2 shows typical applied stress-deflection curves for the T-joints under tensile pullout loading. The $x$-axis is the deflection ( $\delta$ ) and $y$-axis is the maximum nominal stress which is calculated using equation (1). It can be seen from the diagrams, the stress $(\sigma)$-deflection $(\delta)$ behaviour is sensitive to the composite T-joint architectures. 3D woven T-joint always shows the best performance compared with other type T-joints. When the defection $(\delta)$ is less than a certain value, a linear relationship exists between the deflection $(\delta)$ and the applied stress $(\sigma)$ produced by the load. The slope of the $\sigma-\delta$ curves (or 'stiffness') is almost the same when the applied stress $(\sigma)$ is less than around $65 \mathrm{MPa}$ (or $\delta<0.8 \mathrm{~mm}$ ) for the joints (Base, PE and Tufted). In other words, the 'stiffness' appeared in the linear stage is not influenced by the veil layer or tufting. In the $3 \mathrm{D}$ woven T-joint, the slope of the $\sigma-\delta$ curves is almost the same as in that of the $\sigma-\delta$ curves from above types of T-joint, although the slope of the $\sigma-\delta$ curve begins to decrease at a higher applied stress. 
Fig. 2 Typical stress-deflection curves of composite T-joints with different toughening architectures. At least five tests were performed for each type of T-joint

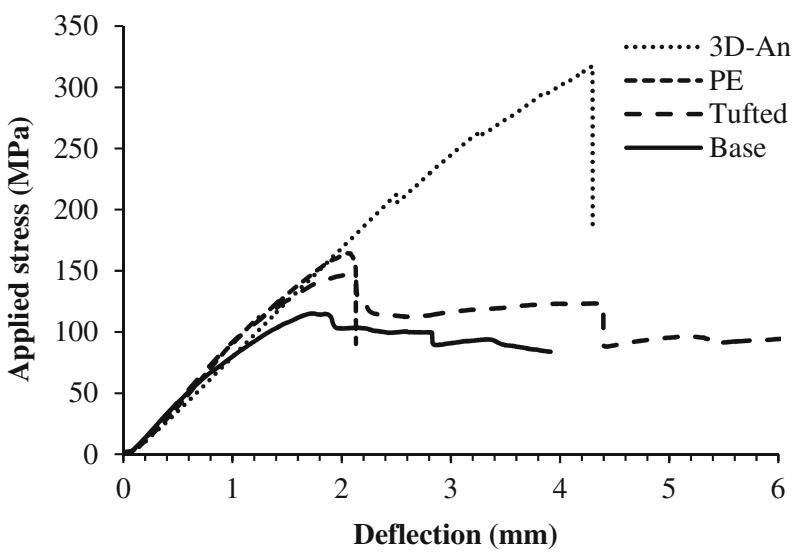

Damage initiation within the T-joint can be determined by the point where the curve's slope starts to decrease. The reduction in the curve's slope is associated with initiation of delamination cracks developed in the T-joint and it continues until the maximum pull-out load is reached. The applied stress value for the reduction of the curve's slope depends upon the type of the composite T-joint. For the Base specimen, the slope of the curve starts to decrease at the applied stress of around $65 \mathrm{MPa}, 90 \mathrm{MPa}$ for the PE veil specimen and $95 \mathrm{MPa}$ for the tufted T-joints. In the 3D woven T-joint, the slope of the curve starts to decrease at around $210 \mathrm{MPa}$.

The mean value of the measured maximum pull-out load for all T-joint is shown in Fig. 3. The type Base specimen is the control specimen to which all other specimen configurations were compared. It can been seen that the type 3D-An specimen shows the highest pull-out strength among all the tested specimens and its strength is increased by $171 \%$ when compared to the type Base specimen. The second is the type PE T-joint containing a polyester veil in the flange-skin interface with an increase of $44 \%$ in the pull-out strength while the type Tufted specimen shows a $27 \%$ increase in the pull-out strength.

The following can be deduced from the analysis of the test results. The through-thickness direction reinforcement (3D woven specimen) in the web significantly increases the strength to failure comparing to other type specimens and the deflection is significantly increased as well. The samples with the PE veils also show higher strength compared to the type Base specimen.

Fig. 3 Strength and defection of T-joints with different reinforcement configurations under static loading

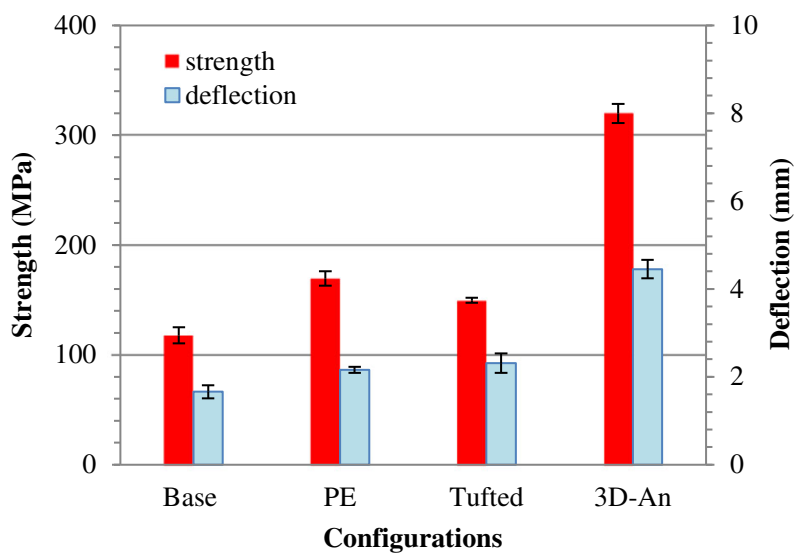


The location where the reinforcement is applied in the T-joint is important in improving its mechanical properties. The tensile pull-out strength in the type Tufted specimen is also improved, but much less compared to $3 \mathrm{D}$ woven specimen in that the tufting yarns in the through-thickness direction are applied only on the flange-skin-stiffener. All these test results provide experimental evidence for the validation of the FE results, which are discussed in later section.

\subsection{Stress-Life}

Fatigue test results in terms of applied stress and number of cycles to failure were plotted for each specimen to produce $S-N$ curves for all joint type. The four sets of data were plotted together in Fig. 4 along with a regression fit for each. The $R^{2}$ values for the regression lines are 0.78 for Base, 0.84 for PE, 0.85 for Tufted and 0.97 for 3D-An, respectively. The results from the static tests were also plotted together at cycle number $n=1$. All curves show the same trend. Increasing fatigue load leads to the decrease in the number of cycles to failure. Fatigue life performance of composite T-joints is significantly influenced by reinforcement configurations.

Fatigue strength is improved when different toughing techniques (e.g. interlaminar veil, tufting and $3 \mathrm{D}$ weave) are applied. The increasing rate in fatigue strength changes with the number of stress cycles. Figure 5 compares the increasing rate in fatigue strength at different stress cycles that are extracted in terms of the best fit of $S-N$ curves in Fig. 4. The best performance is seen in 3D woven T-joint with almost $40 \%$ improvement of fatigue life for one million stress cycles. The interlaminar veil in the flange and skin bond line increases the fatigue strength, but not very significant (4\% increase) at high stress cycles. The tufting technique causes about $10 \%$ reduction in applied stress compared to the base specimen. The tufting or stitching may cause localised fibre damage from the needle penetration and discontinuity at the stitching point; the resin rich pocket is created due to the presence of tuft yarns. All these will reduce its inerlaminar properties.

For a given configuration, e.g. 3D-An, the improvement level of fatigue performance is decreased with increasing the number of fatigue cycles.

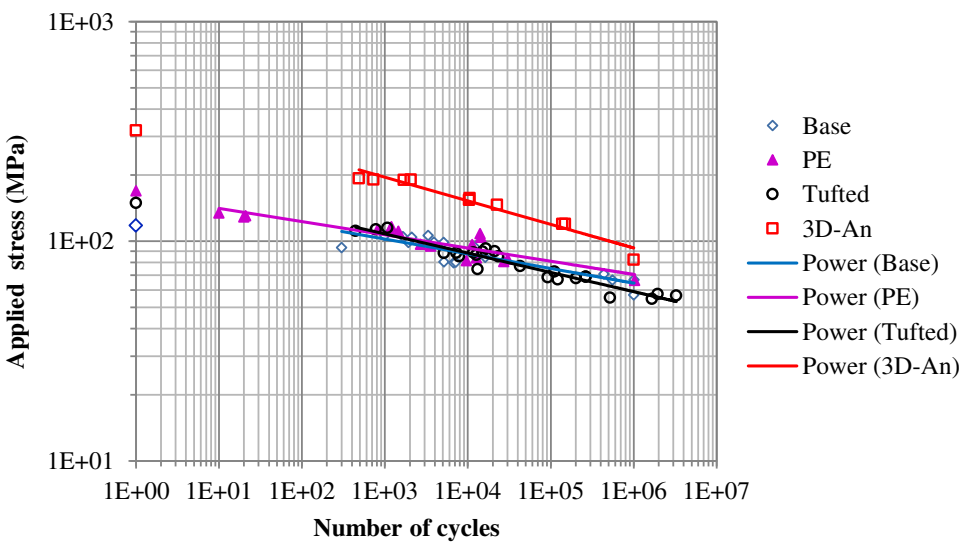

Fig. $4 S-N$ data and regression fits for all type T-joint specimens 
Fig. 5 Comparison of fatigue performance increasing rate for different type of T-joints at different stress cycles that are extracted in terms of the best fit of $S-N$ curves in Fig. 4

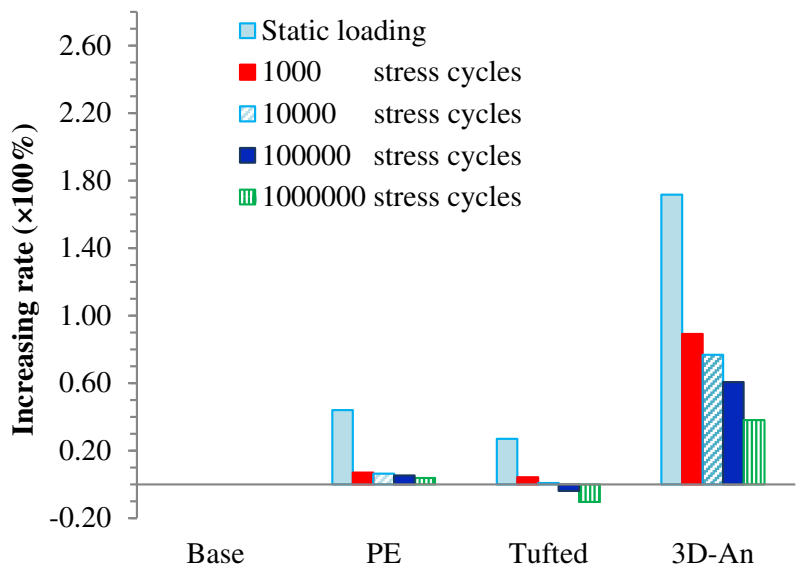

\subsection{Damage and Failure}

Failure modes of composite T-joints were investigated and the results show that the failure modes in fatigued specimens were the same as seen in the static tests for all specimens. Delamination crack path in the static and fatigue tests of T-joint was very similar. The crack always is initiated on the corner of the T-joint due to higher stresses occurring in this region. For specimens with no through thickness reinforcements in the web, after initial propagation in the web the crack propagation slowed down and then started to propagate in the flange-skin bond line. The cracks are clearly seen in the web as shown in Fig. 6a, b and c while there is no crack formed in the web for 3D woven specimen (Fig. 6d) because delamination crack is difficult to propagate in the central line of the web.

\section{Finite Element Modelling of Composite T-Joints}

\subsection{Geometry and Boundary Conditions}

The T-joint illustrated in Fig. 1 is used as the baseline configuration for this study. This T- joint is subjected to tensile pull-out loading along the web. The skin part is considered to be supported near the two ends of the T-joint, as indicated in Fig. 1.

The flange and skin parts consist of five layers of equal thickness arranged in a stacking sequence of $\left[45^{\circ} /-45^{\circ}\right]_{5}$ while the web consists of 10 -layer $\left[45^{\circ} /-45^{\circ}\right]_{10}$ plate. The outer stiffener consists of 5-layer unidirectional (UD) $\left[0^{\circ}\right]_{5}$, which is used to prevent large deflection that may not be representative of the larger structure.

A finite element analysis was performed on composite T-joints using ABAQUS software [29]. Two types of local coordinate systems are used to describe the orientations of each ply. On the corner the cylindrical coordinate system is used. In this coordinate system, the 1,2 , and 3 directions refer to the radial $(\mathrm{R})$, circumferential $(\mathrm{T})$, and axial directions $(\mathrm{Z})$, respectively. In the web, flange, skin and stiffener the rectangle coordinate system is used and the 1,2 , and 3 directions refer to the $\mathrm{X}, \mathrm{Y}$ and $\mathrm{Z}$, respectively. For both coordinate systems, the fibre direction is oriented along axis 2 while directions 1 and 3 correspond to thickness and width directions, 


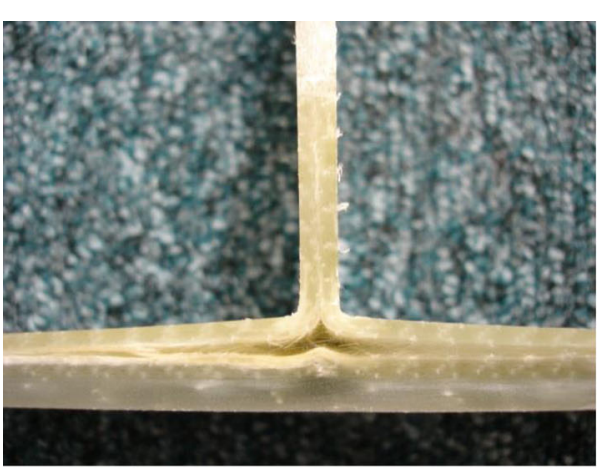

(a)

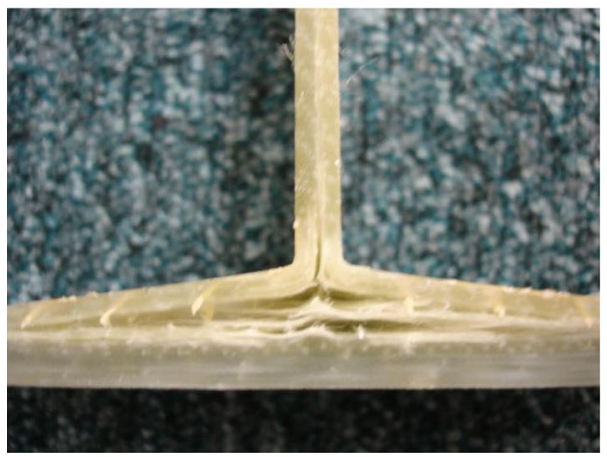

(c)

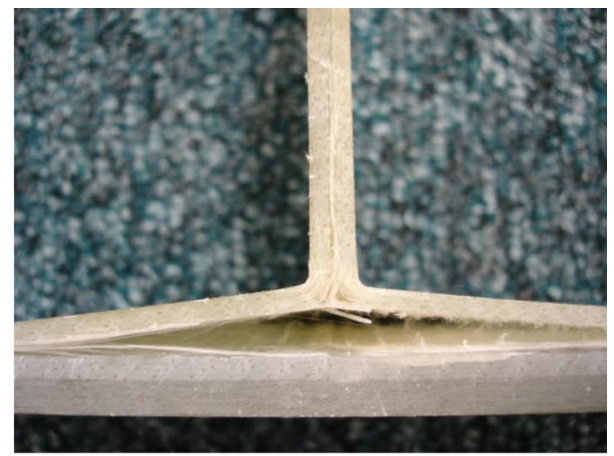

(b)

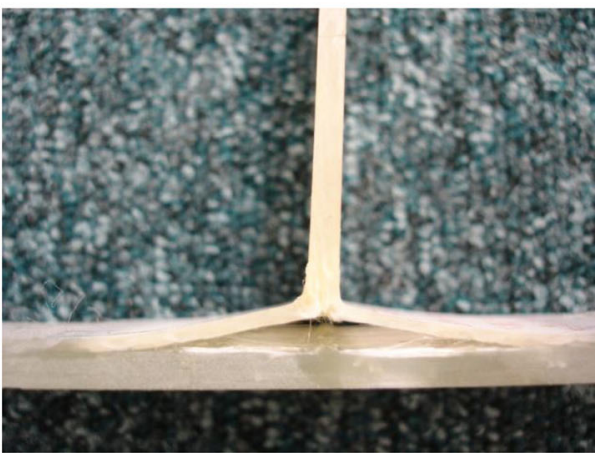

(d)

Fig. 6 Photographs showing crack propagation paths depending upon the T-joint configuration: (a) baseline type T-joint; (b) polyester veil T-joint; (c) tufted T-joint; (d) 3D-woven T-joint. Crack growth paths include the central line of the web and the flange-skin bond line for the cases of (a), (b) and (c) while the crack growth path is only along the flange-skin bond line when the web containing the yarns in through-thickness direction

respectively. The coordinate system used in the FE modelling is shown in Fig. 7. Under this coordinate system the engineering constants for the composite material are: the elastic moduli $E_{1}=E_{3}=9 \mathrm{GPa}, E_{2}=38 \mathrm{GPa}$; Poisson's ratios $v_{13}=v_{23}=0.3, v_{12}=0.071$; the shear moduli $G_{12}=G_{23}=3.6 \mathrm{GPa}, G_{13}=3.46 \mathrm{GPa}$, respectively. The elastic modulus and Poisson's ratio for the epoxy resin are equal to $4 \mathrm{GPa}$ and 0.34 , respectively.

The FE simulations were run under displacement-controlled loading (vertical direction) by applying an increasing tensile displacement along the web. To simulate the fixture roller bars, the skin surface is considered to be restricted in the vertical direction at both sides of the web with $50 \mathrm{~mm}$ distance from the centre. Three elements were used in the thickness direction and an eight-node linear brick element (C3D8R) was utilised. The detailed mesh of the model with the kinematic and loading boundary conditions is shown in Fig. 7.

\subsection{Modelling Delamination of T-Joints}

For composite T-joints, initial delamination cracks are always initiated at the joint's corners due to the maximum stresses developed in this region. These cracks may propagate along the flange-skin bond line only or along both the central line of the web and the flange-skin bond 


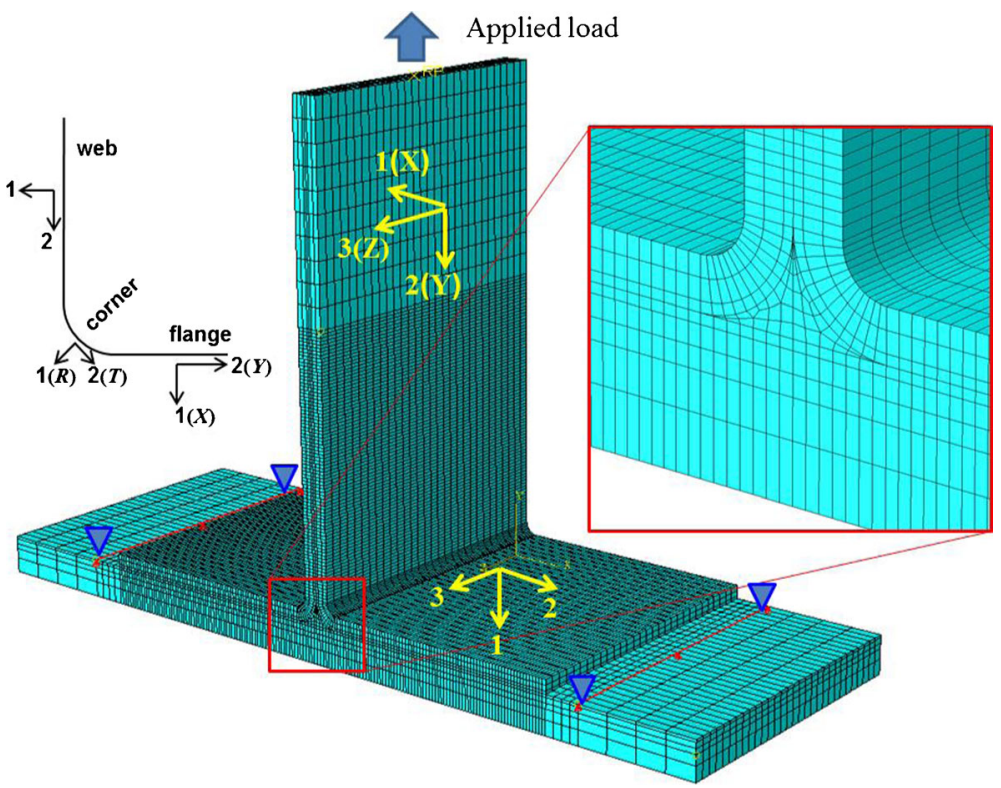

Fig. 7 Diagram showing FE meshing, boundary conditions and local coordinate system of the T-joint FE model

line, depending upon the T-joint reinforced configurations. Initiation and growth of delamination cracks in the composite $\mathrm{T}$-joint are modelled using cohesive zone elements. Linear elastic traction-separation behaviour is used to model the interface where the delamination is expected to occur. The traction-separation model in ABAQUS assumes initially linear elastic behaviour followed by damage initiation and evolution.

The initiation of delamination damage can be estimated using the quadratic nominal stress criterion defined by the following expression [29]

$$
\left\{\frac{\left\langle t_{n}\right\rangle}{t_{n}^{0}}\right\}^{2}+\left\{\frac{t_{s}}{t_{s}^{0}}\right\}^{2}+\left\{\frac{t_{t}}{t_{t}^{0}}\right\}^{2}=1
$$

where $t_{n}^{0}$ is the interlaminar normal tensile strength, $t_{s}^{0}$ and $t_{t}^{0}$ are shear strengths in the two transverse directions.

Crack growth is described using a linear softening fracture-based law, where a mixed mode fracture energy criterion is used. Failure under mixed-mode conditions is governed by a power law interaction of the energies required to cause failure in the individual modes. It is given by the following expression [29]

$$
\left\{\frac{G_{n}}{G_{n}^{c}}\right\}^{\alpha}+\left\{\frac{G_{s}}{G_{s}^{c}}\right\}^{\alpha}+\left\{\frac{G_{t}}{G_{t}^{c}}\right\}^{\alpha}=1
$$

where $G_{n}^{c}$ is the normal strain energy release rate, $G_{s}^{c}$ and $G_{t}^{c}$ are shear strain energy release rates in the two transverse directions; $\alpha$ is assumed to be equal to 1 , but could be 2 . The effect of $\alpha$ value on the load-deflection curve was studied and the variation of $\alpha$ values shows less effect. Various fracture energy values are selected to investigate its effect on crack propagation. Selecting 'appropriate' stress-based or fracturebased remains a debating issue. 


\section{Calculation Results and Discussion}

\subsection{Analysis of Interlaminar Stresses}

The stresses within the different regions in the T-joint were computed using the FE model developed in the previous section and the calculated results are now discussed. Figure 8 illustrates the locations where the stresses were measured, the stress $\sigma_{11}$ contours that indicate high stress formed at the corner. The regions of interest are: line $\mathrm{AB}$ (the central line of the web); arc $\mathrm{BC}$ (the interface between the corner and epoxy resin rich pocket); line $\mathrm{CD}$ (the bonded connection between skin and flange). The variation of the normal stress $\sigma_{11}$ in the through thickness direction around the corner is also addressed because of the danger of developing catastrophic cracks. The positions of interest are: arc $\mathrm{B}_{1} \mathrm{C}_{1}$ (the interface between layer 2 and layer 3, counted from outer surface of the flange); $\operatorname{arc} \mathrm{B}_{2} \mathrm{C}_{2}$ (the interface between layer 4 and layer 5). The stresses developed in those regions were numerically obtained. These stress values are then plotted to determine their distributions along those identified critical paths.

Figure 9 shows the distribution of the stresses (normal stress $\sigma_{11}$ and two shear stresses $\sigma_{12}$ and $\sigma_{13}$ ) along the path $\mathrm{ABCD}$ where delamination can be triggered according to equation (2). It can be seen from the figure, in the web region (path $A B$ ), the stresses are hardly seen until near the corner where a sudden increase in the stresses is seen. There is a big stress jump in the region of the corner (path BC) and after the corner only the shear stresses are seen except near the end of the flange where there is a discontinuity. The higher stresses formed at the corner will initiate delamination cracks when the damage criterion of equation (2) is met. This is in agreement with delamination cracks observed in the experiments.

In Fig. 10, the stress $\sigma_{11}$ distributions along different paths at the corner (arcs: $\mathrm{BC}, \mathrm{B}_{1} \mathrm{C}_{1}$ and $\mathrm{B}_{2} \mathrm{C}_{2}$ in Fig. 8) are shown in great detail. For path $\mathrm{BC}$ and path $\mathrm{B}_{1} \mathrm{C}_{1}$, the $\sigma_{11}$ reaches its maximum value at $\theta=22.5^{\circ}$ while the maximum value is seen at $\theta=67.5^{\circ}$ for path $\mathrm{B}_{2} \mathrm{C}_{2}$. The $\sigma_{11}$ stress level is significantly decreased in the through thickness direction, which confirms that the preferred site for the formation of delamination crack is the interface between the corner and epoxy resin rich pocket. In terms of Fig. 10, the multi-cracks may be formed due to the presence of high levels of stress near the epoxy resin rich pocket. The normal stress is always larger than shear stress and consequently the normal stress dominates the initiation of delamination cracks.
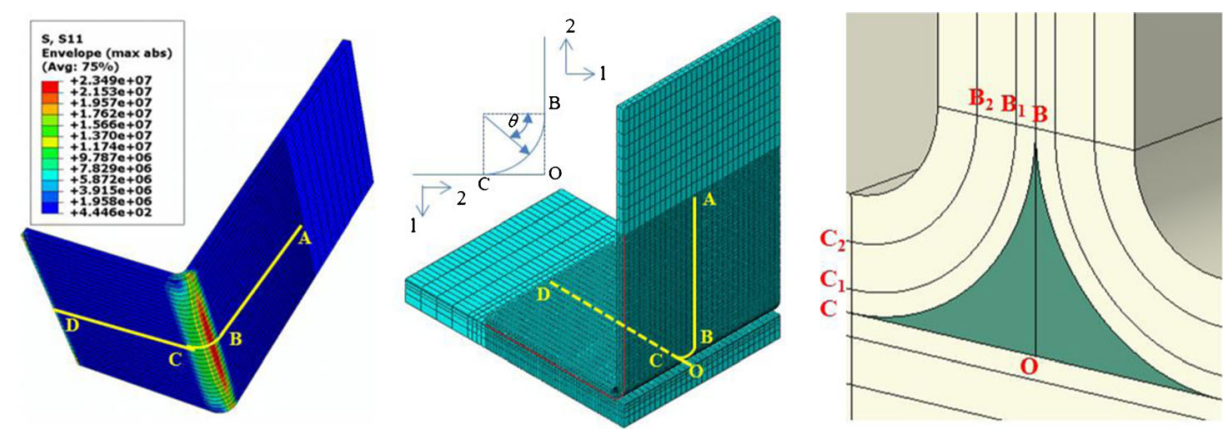

Fig. 8 Diagram showing the stress contours $\left(\sigma_{11}\right)$ indicating high stresses on the corner and the paths where the stresses are measured 
Fig. 9 The distribution and magnitude of the stresses $\left(\sigma_{11}, \sigma_{12}\right.$ and $\sigma_{13}$ ) along the path ABCD of Fig. 8 at load $=2000 \mathrm{~N}$

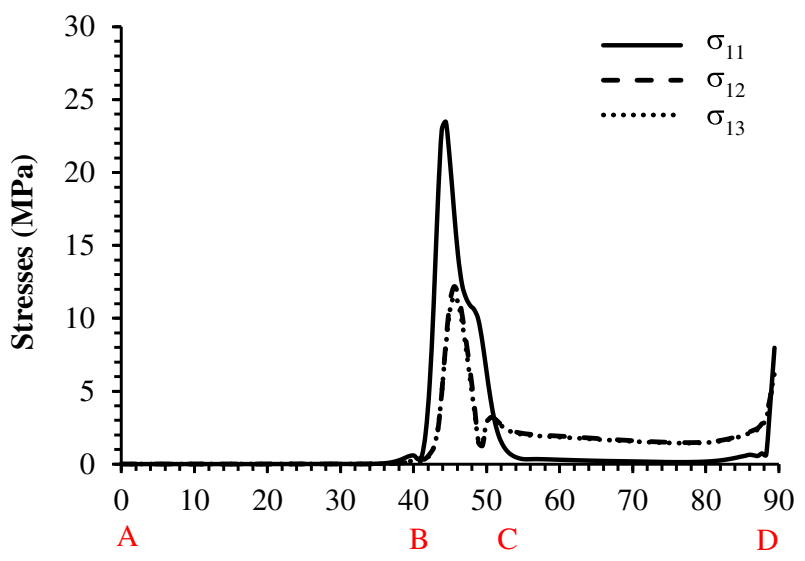

Distance from point A along path $\mathrm{ABCD}(\mathbf{m m})$

\subsection{Effect of Interlaminar Fracture Toughness}

Delamination is initiated when the interlaminar stress exceeds the interlaminar strength. The subsequent propagation of delamination cracks depends upon the interlaminar fracture toughness $\left(G_{\mathrm{IC}}\right)$ as delamination is actually an energy dependant mechanism. The effect of interlaminar fracture toughness is discussed below.

Figure 11 shows the effect of interlaminar fracture energy on load-deflection curves. It is observed that the ultimate nominal stress to failure is significantly increased when the critical strain energy release rate $G_{\mathrm{IC}}$ is increased from $300 \mathrm{~J} / \mathrm{m}^{2}$ to $600 \mathrm{~J} / \mathrm{m}^{2}$. The peak stress is increased by approximately $35 \%$. The calculated results predict that the crack growth rate is decreased with increasing interlaminar fracture toughness $\left(G_{I C}\right)$ and fatigue life performance of T-joints will be increased accordingly. This has been confirmed by the experimental results, e.g. tufting and veil layer techniques increasing the pull-out strength significantly (see Fig. 3).

Fig. 10 The distribution and magnitude of stress $\sigma_{11}$ along different paths shown in Fig. 8 at load $=2000 \mathrm{~N}$

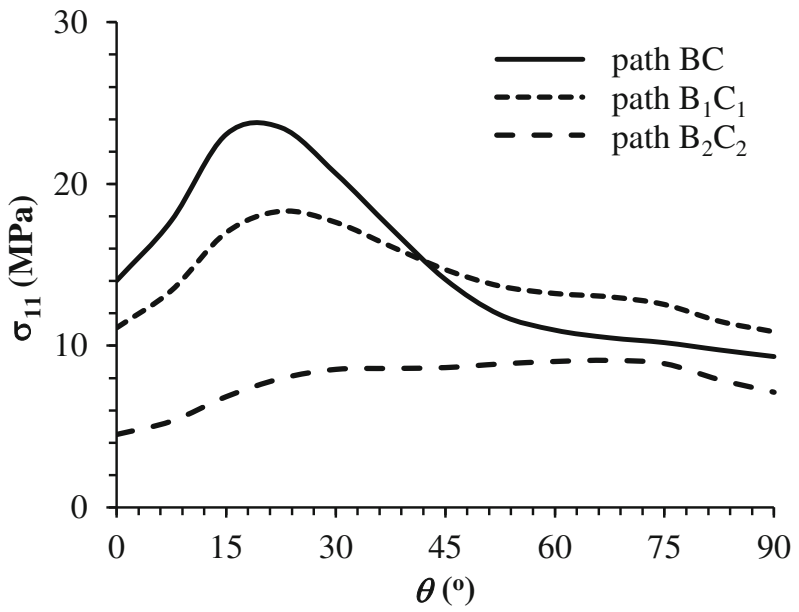


Fig. 11 Stress-deflection curves from FE analysis showing that the nominal applied stress is increased with the increase of interlaminar fracture energy

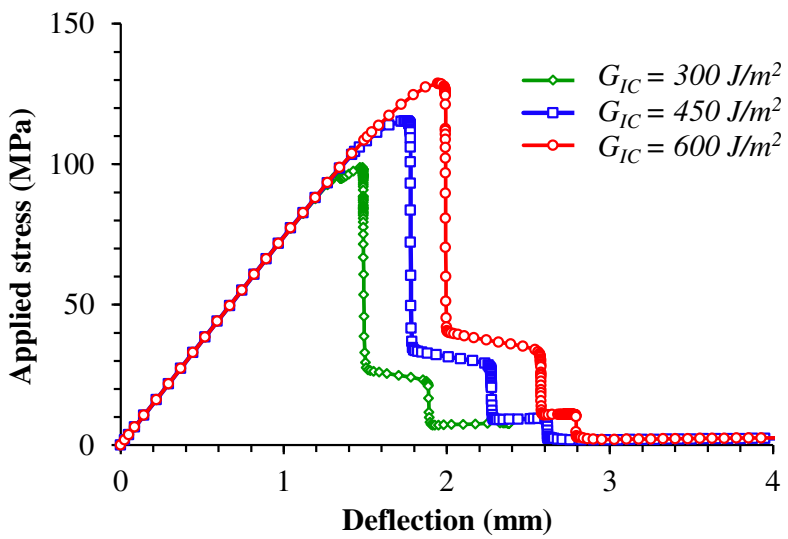

\subsection{Effect of the Web with through Thickness Reinforcement}

The tufting technique improves delamination resistance resulting from the crack bridging by zfibres, which reduces the driving force for crack growth. However, the localised fibre damage from the needle penetration and the resin rich pocket at tufted yarns lead to the reduction in fatigue life performance due to its direct interaction with the crack growth path. The details for modelling the effect of tufted yarns can be found in references [16].

The through thickness reinforcement in the web can significantly increase the strength both in static and fatigue loading, e.g. 3D-An T-joint (see Fig. 5). Crack growth was only along the bonded connection between skin and flange; no crack growth was seen in the web (see Fig. 6). To model crack growth in the 3D angle interlock T-joint, a tie constraint was imposed between pairs of surfaces (the central line of the web) to simply represent its structural features.

Figure 12a shows that the applied stress is increased dramatically when the through thickness reinforcement is applied to the web. The pull-out strength increased from $128 \mathrm{MPa}$ (web with no through thickness reinforcement) to $242 \mathrm{MPa}$ (web with through thickness reinforcement). The FE result shows a high correlation with the experimental observation shown in Fig. 12b, where the web is reinforced in the through thickness direction for a 3D-An T-joint while the web is not reinforced for the PE T-joint.

It can be concluded that the technique that can reinforce the T-joint's web in the through thickness direction will enhance the tensile pull-out strength and improve fatigue performance of the T-joint; the 3D woven T-joint is a good example.

\section{Conclusions}

Fatigue behaviour of T-joints under tensile pull-out loading has been studied. Four types of T-joints (baseline, polyester veil, tufted and 3D weave) were selected to investigate its fatigue performance and failure mechanisms. The 3D angle interlock T-joint was found to have the best performance in both static and fatigue loading. Increasing the static properties increases fatigue performance while the increasing rate in life performance is changed with the number of fatigue cycles.

The location for through-thickness reinforcement is very important to improve fatigue performance of composite T-joints. Fatigue performance is significantly improved for the web with through-thickness reinforcement (e.g. 3D angle interlock T-joint) while fatigue 
Fig. 12 Stress-deflection curve showing that the nominal applied stress is significantly increased when the web is reinforced in through-thickness direction: (a) FE simulation; (b) experimental observations

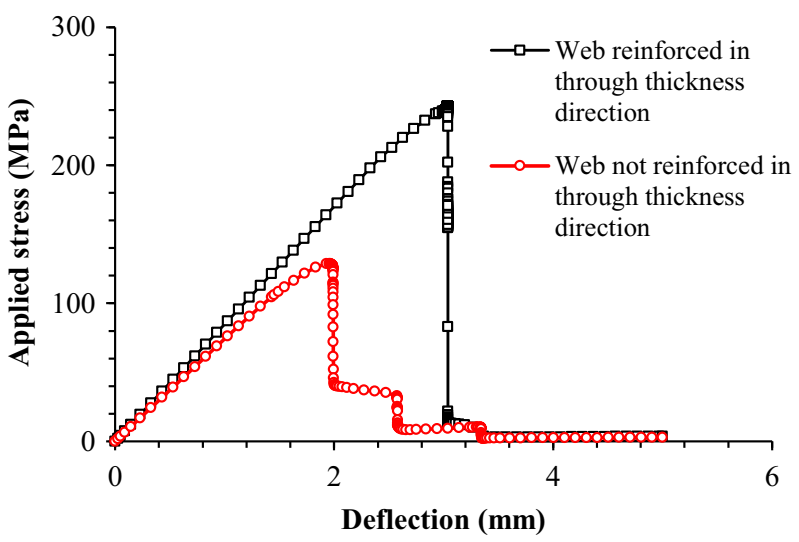

(a)

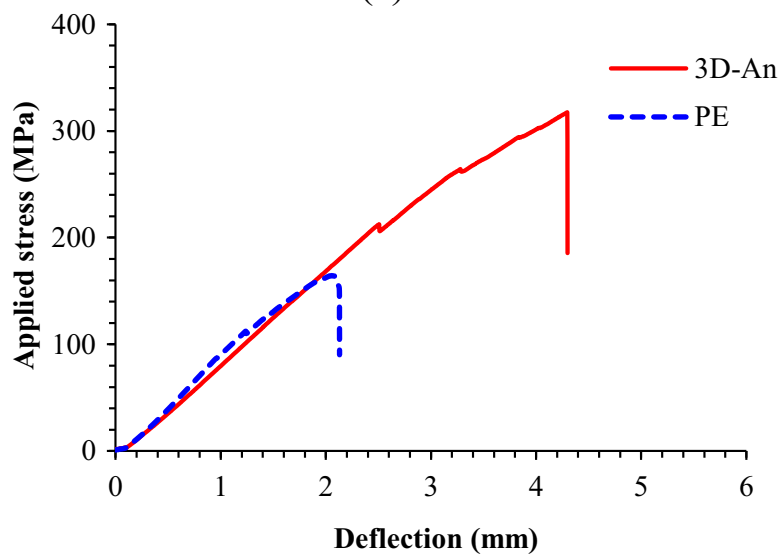

(b)

performance is decreased if the through-thickness reinforcement is applied to the flange-skin regions (e.g. tufted T-joint). It can be concluded that the techniques that can reinforce a Tjoint's web in the through thickness direction will enhance the tensile pull-out strength and improve fatigue performance of the T-joint.

A predictive FE model was developed that can determine the strength of composite Tjoints. The FE predictions were validated by experimental measurements and observations that confirmed the validity of the assumptions and simplifications introduced in the FE simulation, although it remains difficult to accurately capture all the non-linearities and fluctuations seen in the measured load-deflection response. The results show that the FE predictions are highly consistent with experimental observations.

The veil layer significantly increases the ultimate strength under static load (delaying delamination initiation) but fatigue performance at high stress cycles is increased but not significantly.

Acknowledgments The authors acknowledge the research grant from EPSRC (EP/H018662/1) for this research. 
Open Access This article is distributed under the terms of the Creative Commons Attribution 4.0 International License (http://creativecommons.org/licenses/by/4.0/), which permits unrestricted use, distribution, and reproduction in any medium, provided you give appropriate credit to the original author(s) and the source, provide a link to the Creative Commons license, and indicate if changes were made.

\section{References}

1. Sesto E., Casale C.: Exploitation of wind as an energy source to meet the world's electricity demand. J. Wind Eng. Ind. Aerodyn. 74-76, 375-387 (1998)

2. Chou J.-S., Tu W.-T.: Failure analysis and risk management of a collapsed large wind turbine tower. Eng. Fail. Anal. 18, 295-313 (2011)

3. Mouritz A.P., Leong K.H., Herszberg I.: A review of the effect of stitching on the in-plane mechanical properties of fibre-reinforced polymer composites. Compos. Part A. 28(12), 979-991 (1997)

4. Mouritz A.P., Bannister M.K., Falzon P.J., Leong K.H.: Review of applications for advanced threedimensional fibre textile composites. Compos. Part A. 30(12), 1445-1461 (1999)

5. Burns L., Mouritz A., Pook D., Feih S.: Strength improvement to composite T-joints under bending through bio-inspired design. Compos. Part A. 43(11), 1971-1980 (2012)

6. Leong K., Ramakrishna S., Huang Z., Bibo G.: The potential of knitting for engineering composites -a review. Compos. Part A. 31(3), 197-220 (2000)

7. Mouritz A.P.: Review of z-pinned composite laminates. Compos. Part A. 38(12), 2383-2397 (2007)

8. Kuwata M., Hogg P.J.: Interlaminar toughness of interleaved CFRP using non-woven veils: part 1. Mode-I Testing. Compos. Part A. 42(10), 1551-1559 (2011)

9. Allegri G., Zhang J.: On the delamination and debond suppression in structural joints by Z-fibre pinning. Compos. Part A. 38(4), 1107-1115 (2007)

10. Baldi A., Airoldi A., Crespi M., Iavarone P., Bettini P.: Modelling competitive delamination and debonding phenomena in composite T-joints. Procedia Eng. 10, 3483-3489 (2011)

11. Bianchi F., Koh T.M., Zhang X., Partridge I.K., Mouritz A.P.: Finite element modelling of z-pinned composite T-joints. Compos. Sci. Technol. 73, 48-56 (2012)

12. Bianchi F., Zhang X.: A cohesive zone model for predicting delamination suppression in z-pinned laminates. Compos. Sci. Technol. 71, 1898-1907 (2011)

13. Chen J.: Simulation of multi-directional crack growth in braided composite T-piece specimens using cohesive models. Fatigue Fract. Eng. Mater. Struct. 34, 123-130 (2010)

14. Chen J., Ravey E., Hallett S., Wisnom M., Grassi M.: Prediction of delamination in braided composite Tpiece specimens. Compos. Sci. Technol. 69(14), 2363-2367 (2009)

15. Wang Y., Soutis C., Hajdaei A., Hogg P.J.: Finite element analysis of composite T-joints used in wind turbine blades. Plast Rubber Compos. 44(3), 87-97 (2015)

16. Wang, Y. and Soutis, C.: Modelling the effect of tufted yarns in composite T-joints. Eng. Computat. Mech. (2016)

17. Shenoi R.A., Read P.J.C.L., Hawkins G.L.: Fatigue failure mechanisms in fibre-reinforced plastic laminated tee joints. Int. J. Fatigue. 17(6), 415-426 (1995)

18. Shenoi R.A., Hawkins G.L.: Influence of material and geometry variations on the behavior of bonded tee connections in FRP ships. Composite. 23(5), 335-345 (1992)

19. Marcadon V., Nadot Y., Roy A., Gacougnolle J.L.: Fatigue behaviour of T-joints for marine applications. Int. J. Adhes. Adhes. 26, 481-489 (2006)

20. Read P.J.C.L., Shenoi R.A.: Fatigue behaviour of single skin FRP tee joints. Int. J. Fatigue. 21, 281-296 (1999)

21. Rao V.V.S., Veni K.K., Sinha P.K.: Behaviour of composite wing T-joints in hygrothermal environments. Aircraft Engineering and Aerospace Technology. 76(4), $404-413$ (2004)

22. Rispler A.R., Steven G.P., Tong L.: Failure analysis of composite T-joints including inserts. J. Reinf. Plast. Compos. 16(18), 1642-1658 (1997)

23. Blake J.I.R., Shenoi R.A., House J., Turton T.: Progressive damage analysis of tee joints with viscoelastic inserts. Compos. Part A. 32, 641-653 (2001)

24. Cartie D.D.R., Dell'Anno G., Poulin E., Partridge I.K.: 3D reinforcement of stiffener-to-skin T-joints by Zpinning and tufting. Eng. Fract. Mech. 73, 2532-2540 (2006) 
25. Dharmawan F., Thomson R.S., Li H., Herszberg I., Gellert E.: Geometry and damage effects in a composite marine T-joint. Compos. Struct. 66, 181-187 (2004)

26. Kesavan A., Deivasigamani M., John S., Herszberg I.: Damage detection in T-joint composite structures. Compos. Struct. 75, 313-320 (2006)

27. Hajdaei A.: Extending the Fatigue Life of a T-joint in a Composite Wind Turbine Blade. PhD Thesis, The University of Manchester, Manchester (2013)

28. Ugural A.C., Fenster S.K.: Advanced Strength and Applied Elasticity. Upper Saddle River, New Jersey Prentice-Hall PTR (1995)

29. ABAQUS Analysis User's Manual. Dassault Systèmes Simulia Corp. (2012) 